\title{
FERTILIZANTE DE LIBERAÇÃO LENTA NA FORMAÇÃO DE MUDAS DE MARACUJAZEIRO 'AMARELO'
}

\author{
Fertilization of low liberation in cutting formation of yellow passion fruits
}

\author{
Vander Mendonça1, Mauro da Silva Tosta², João Riquelme Machado², Sidney Antônio Roseiro Goulart Júnior², \\ Joel da Silva Tosta², Guilherme Augusto Biscaro ${ }^{3}$
}

\begin{abstract}
RESUMO
A prática de adubações, além de se constituir num fator indispensável para o desenvolvimento das mudas, acelera consideravelmente o crescimento das mesmas, reduzindo assim os custos de produção. Com o objetivo de avaliar a produção de mudas de maracujazeiro ‘Amarelo' com adubações com o fertilizante Entec ${ }^{\circledR}$, conduziu-se um experimento em viveiro de formação de mudas a céu aberto no setor de produção da Universidade Estadual de Mato Grosso do Sul (UEMS), Mato Grosso do Sul. Foram testadas cinco doses de Entec ${ }^{\circledR} 0 ; 3 ; 6 ; 9$ e $12 \mathrm{~kg} \mathrm{~m}^{-3}$ de substrato. Foi utilizado o delineamento experimental em blocos ao acaso com cinco tratamentos, quatro repetições e cinco plantas por parcela. Após 120 dias da semeadura avaliaram-se as características: altura de plantas $(\mathrm{cm})$; número de folha/planta, matéria seca da parte aérea, da raiz e total (g/planta). Foi observado que a utilização de adubações nitrogenada com Entec ${ }^{\circledR}$ em dosagem de até $6,0 \mathrm{~kg} \mathrm{~m}^{-3}$ de substrato garante melhor qualidade na formação e no desenvolvimento das mudas de maracujazeiro 'amarelo'.
\end{abstract}

Termos para indexação: Nutrição, propagação, adubação, Passiflora edulis Sims f. flavicarpa Degener.

\begin{abstract}
Aiming to evaluate the production of yellow passion fruits cuttings with covering Entec ${ }^{\circledR}$ fertilization an experiment was carried out in exposed sky condition at orchard of Universidade Estadual de Mato Grosso do Sul (UEMS), Mato Grosso do Sul. It was tested five Entec ${ }^{\circledast}$ dosages: $0 ; 3 ; 6 ; 9$ and $12 \mathrm{~kg} \mathrm{~m}^{-3}$. A randomized block design was used with five treatments, with four replications and five plants per plot. After 120 days of seed germination it was evaluated the following characteristics: plant high $(\mathrm{cm})$, number of leaves/plant, dry weight of aerial part, roots and total (g/plant). It was observed that the utilization of Nitrogen fertilization with Entec ${ }^{\circledR}$ until $6,0 \mathrm{~kg} \mathrm{~m}^{-3}$ warranty best quality and better development of stem and of passion fruit.
\end{abstract}

Index terms: Nutrition, propagation, adubation, Passiflora edulis Sims f. flavicarpa Degener.

\section{(Recebido em 10 de janeiro de 2006 e aprovado em 24 de novembro de 2006)}

\section{INTRODUÇÃO}

O maracujazeiro ‘Amarelo’ é uma frutífera com ampla adaptação no Brasil, sendo considerada uma cultura que emprega grande quantidade de mão-de-obra, caracterizando-a como uma atividade agrícola familiar. Sua expansão nem sempre é planejada, acarretando grandes perdas de matéria-prima produzida, além da utilização de material genético (mudas) de baixa qualidade.

A nutrição exerce papel fundamental no desenvolvimento das plantas, principalmente a adubação nitrogenada (SIQUEIRA et al., 2002).

A quantidade de nitrogênio em forma disponível no solo é muito pequena, segundo Lopes (1989). De acordo com Malavolta (1980), a maior parte do nitrogênio orgânico no solo, aparentemente parece estar ligado à lignina (que é um derivado de carboidrato) como um complexo ligno protéico. Este mesmo autor acrescenta que nos solos brasileiros o nitrogênio, na sua maior parte, encontra-se em forma orgânica, a fração mineral (nitratos e $\mathrm{NH}_{4}^{+}$) corresponde apenas a uma pequena parte. Raij (1981) afirma que o nitrogênio inorgânico do solo existente em cada instante, é resultado da decomposição da matéria orgânica.

Quando a planta é deficiente em nitrogênio ocorrem alterações na distribuição de fotoassimilados entre as raízes e a parte aérea, tendo como consequiência o aumento na relação raízes/parte aérea, que é o efeito mais freqüente (RUFTY et al., 1990).

A utilização do nitrogênio para produção de mudas em recipientes tem apresentado bons resultados, principalmente para a produção de porta-enxertos de citros nas suas diferentes fases de crescimento (DECARLOS NETO, 2000) e também na formação de mudas de maracujazeiro (SIQUEIRA et al., 2002).

\footnotetext{
${ }^{1}$ Engenheiro Agrônomo, Dr. Professor Adjunto da Universidade Federal Rural do Semi-Árido/UFERSA - BR 110 - Km 47 - Bairro Pres. Costa e Silva 59625-900 - Mossoró, RN - vander@ufersa.edu.br

${ }^{2}$ Alunos de graduação em Agronomia pela Universidade Estadual de Mato Grosso do Sul/UEMS - Rod. MS 306 - Km 06 - $79.540-000$ - Cassilândia, MS maurosilvatosta@yahoo.com.br, jriquelme@bol.com.br, jrgoulart360@hotmail.com, joeltosta@yahoo.com.br

${ }^{3}$ Engenheiro Agrícola, Dr. Professor Adjunto da Universidade Estadual de Mato Grosso do Sul/UEMS - Rod. MS 306 - Km 06 - $79.540-000$ Cassilândia, MS - gbiscaro@uems.br
} 
Neste contexto, a prática de adubações, além de se constituir num fator indispensável para o desenvolvimento das mudas, acelera consideravelmente o crescimento das mesmas, reduzindo os custos de produção. A eficiência das adubações, principalmente daquelas realizadas em cobertura, depende basicamente das doses e fontes dos adubos utilizados, da capacidade de troca cationnica e das características físicas do substrato.

Uma das alternativas para aumentar a eficiência dessas adubações seria a realização de maior parcelamento, principalmente quando se trata do nitrogênio. Porém, esta prática apresenta um aumento significativo no custo operacional. Outra alternativa seria a utilização de fontes que apresentam uma liberação mais lenta ou controlada dos nutrientes. Um exemplo deste tipo de fertilizante é o Entec $^{\circledR}$.

O Entec ${ }^{\circledR}(15-10-10)$ é um fertilizante com tempo de liberação em torno de 4 meses que contém $26 \%$ de N, sendo $7,5 \%$ na forma de $\mathrm{NO}_{3}$ e $18,5 \%$ na forma de $\mathrm{NH}_{4}$ e também $13 \%$ de S. Pelo fato do Entec ${ }^{\circledR}$ permitir a disponibilidade contínua de nitrogênio para as mudas, durante um maior tempo, existe menor possibilidade de ocorrer deficiência deste nutriente durante o período de formação das mudas, o que dispensaria aplicações parceladas reduzindo assim, os custos operacionais na formação da muda. É um fertilizante indicado tanto para produção de mudas de diversas frutíferas, como ornamentais e oleráceas.

Realizou-se este trabalho com objetivo de Entec ${ }^{\circledR}$ na produção de mudas de maracujazeiro ‘Amarelo', visando a obtenção de mudas de boa qualidade, bem nutridas, com maior resistência e adaptação no campo.

\section{MATERIAL E MÉTODOS}

O experimento foi instalado e conduzido a céu aberto em local próximo ao Setor de produção da Universidade Estadual de Mato Grosso do Sul (UEMS), Cassilândia-MS.

As mudas utilizadas nesta pesquisa foram obtidas de sementes da empresa TOP SEED ${ }^{\circledR}$, sendo utilizado o maracujá redondo amarelo com $85 \%$ de germinação e $100 \%$ de pureza, conforme dados do fabricante. Foram semeadas três (3) sementes por saquinho de polietileno preto com capacidade de $500 \mathrm{~mL}$, com dimensões de $20 \mathrm{~cm}$ de altura e com $10 \mathrm{~cm}$ de diâmetro. $\mathrm{O}$ substrato utilizado no enchimento dos saquinhos para produção da muda foi à base de esterco bovino + solo, na proporção de 1:3 v/v.

Foram testadas cinco doses de Entec ${ }^{\circledR} 0 ; 3 ; 6 ; 9$ e $12 \mathrm{~kg} \mathrm{~m}^{-3}$ de substratos aplicadas ao substrato antes do enchimento dos saquinhos. Foi utilizado o delineamento experimental em blocos, com 4 repetições e cinco plantas por parcela, perfazendo-se um total de 100 (cem) mudas.

Após a germinação, cerca de 15 dias da semeadura, as mudas foram desbastadas deixando-se apenas a mais vigorosa por recipiente.

Os tratos culturais utilizados foram a irrigação (de manhã e a tarde), controle de pragas e doenças e, a monda das plantas daninhas.

Quando as mudas apresentaram condições ideais para serem transplantadas ao campo, cerca de 120 dias após a semeadura, foram avaliadas nas seguintes características: altura da muda $(\mathrm{cm})$; comprimento da raiz (cm); diâmetro do colo (mm); número de folhas (unid); matéria seca da raiz; da parte aérea e total $(\mathrm{g})$.

A determinação da altura da muda foi realizada com uma régua graduada em centímetro, medindo-se a distância entre o colo e o ápice da muda. Na determinação do diâmetro do colo foi utilizado um paquímetro digital com valores expresso em mm.

A matéria seca da raiz e da parte aérea foi obtida após secagem em estufa de circulação forçada de ar a 60 ${ }^{\circ} \mathrm{C}$, até atingirem peso constante, procedendo a pesagem em balança analítica. Com as soma da matéria seca da parte aérea e raiz obteve-se a matéria seca total.

Os resultados foram submetidos à análise de variância e as médias dos dados foram submetidas ao teste de regressão, conforme recomendações de Gomes (2000). As análises foram realizadas pelo programa computacional Sistema para Análise de Variância - SISVAR (FERREIRA, 2000).

\section{RESULTADOS E DISCUSSÃO}

Observa-se pelos dados apresentados na Tabela 1 que as doses de Entec ${ }^{\circledR i n f l u e n c i a r a m ~ s i g n i f i c a t i v a m e n t e ~}$ em todas as variáveis estudadas.

Na Figura 1, observa-se que, conforme se aumentaram as doses de Entec ${ }^{\circledR}$ aplicadas, ocorreu um aumento da altura das mudas. As mudas apresentaram altura máxima estimada de $43,23 \mathrm{~cm}$ quando foi aplicada a dose de $5,45 \mathrm{~kg} \mathrm{~m}^{-3}$ do fertilizante. A partir destas dosagens houve um efeito contrário, caracterizado como super dosagem de N. Para o comprimento da raiz a dose máxima estimada de $4,62 \mathrm{~kg} \mathrm{~m}^{-3}$ do fertilizante proporcionou um comprimento de $20,33 \mathrm{~cm}$ nas raízes (Figura 2). O maior diâmetro do colo $(5,51 \mathrm{~mm})$ das mudas do maracujazeiro foi obtido na dose $3,60 \mathrm{~kg} \mathrm{~m}^{-3}$ do fertilizante (Figura 3). Já o maior número de folhas $(13,77)$ foi obtido quando se utilizou $7,66 \mathrm{~kg} \mathrm{~m}^{-3}$ do fertilizante (Figura 4). 
TABELA 1 - Resumo da análise de variância (Quadrado médio) da altura, comprimento da raiz, diâmetro do colo, número de folhas, matéria seca da parte aérea, matéria seca da raiz e matéria seca total em função de doses de Entec ${ }^{\circledR}$ na produção de mudas de maracujazeiro ‘Amarelo’. Cassilândia-MS, 2005.

\begin{tabular}{lcccccccc}
\hline $\begin{array}{l}\text { Fontes de } \\
\text { Variação }\end{array}$ & GL & $\begin{array}{c}\text { Altura } \\
(\mathbf{c m})\end{array}$ & $\begin{array}{c}\text { Comp. da raiz } \\
(\mathbf{c m})\end{array}$ & $\begin{array}{c}\text { Diâm. do } \\
\text { colo }(\mathbf{m m})\end{array}$ & $\begin{array}{c}\text { Número } \\
\text { de folhas }\end{array}$ & $\begin{array}{c}\text { Matéria seca Matéria seca Matéria seca } \\
\text { da parte } \\
\text { aérea }(\mathbf{g})\end{array}$ & $\begin{array}{c}\text { da raiz }(\mathbf{g}) \\
\text { total }(\mathbf{g})\end{array}$ \\
\hline Entec $^{\circledR}$ & 4 & $526,8063^{* *}$ & $18,64996^{* *}$ & $1,106434^{* *}$ & $20,22174^{*}$ & $10,12045^{* *}$ & $0,1616^{* *}$ & $12,36262^{* *}$ \\
Repetição & 3 & 31,01964 & 3,331712 & 0,631870 & 6,403245 & 1,88026 & 0,007787 & 1,82539 \\
Resíduo & 12 & 41,271902 & 2,972808 & 0,161367 & 5,503791 & 1,373287 & 0,02697 & 1,4950 \\
\hline $\mathrm{CV}(\%)$ & & 20,37 & 9,29 & 7,92 & 19,90 & 23,18 & 26,93 & 21,59
\end{tabular}

** Significativo a $1 \%$ de probabilidade pelo teste F; * Significativo a 5\% de probabilidade pelo teste $\mathrm{F}$.

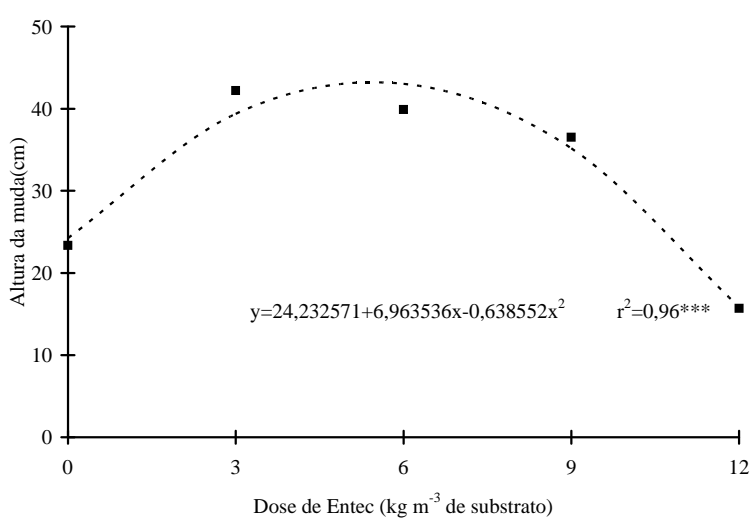

FIGURA 1 - Altura de mudas de maracujazeiro 'Amarelo' em função das doses de Entec ${ }^{\circledR}$. Cassilândia-MS, 2005.

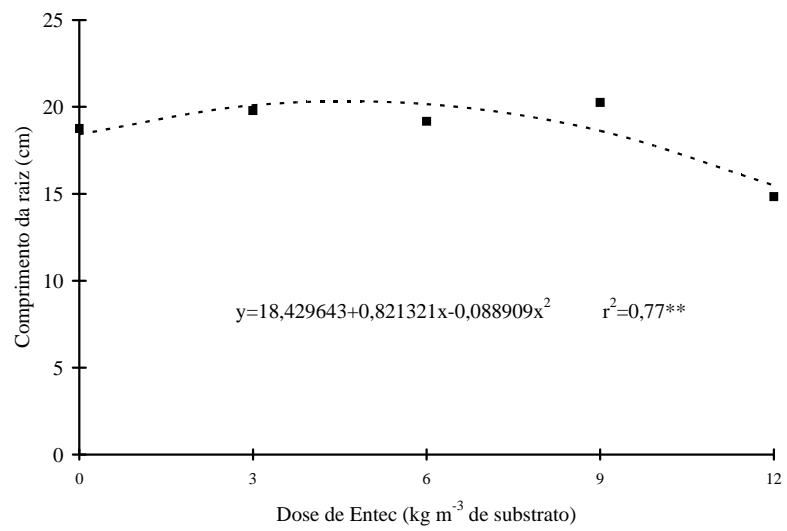

FIGURA 2 - Comprimento da raiz de mudas de maracujazeiro 'Amarelo' em função das doses de Entec ${ }^{\circledR}$. Cassilândia-MS, 2005.

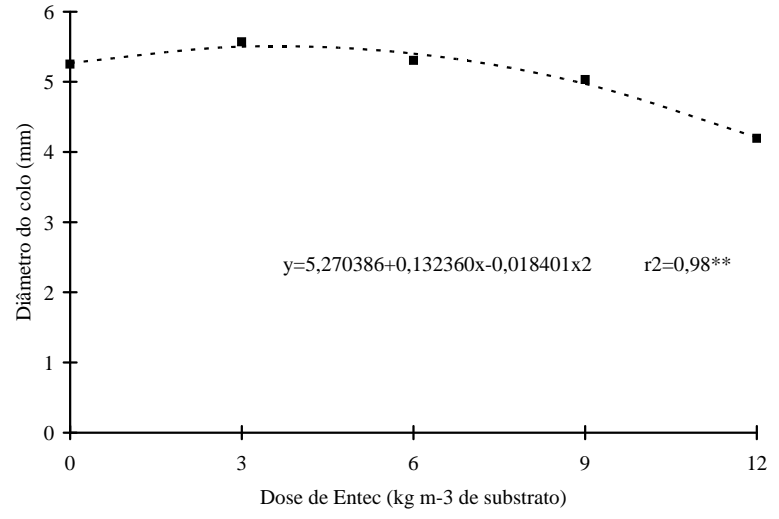

FIGURA 3 - Diâmetro do colo de mudas de maracujazeiro 'Amarelo' em função das doses de Entec ${ }^{\circledR}$. Cassilândia-MS, 2005.

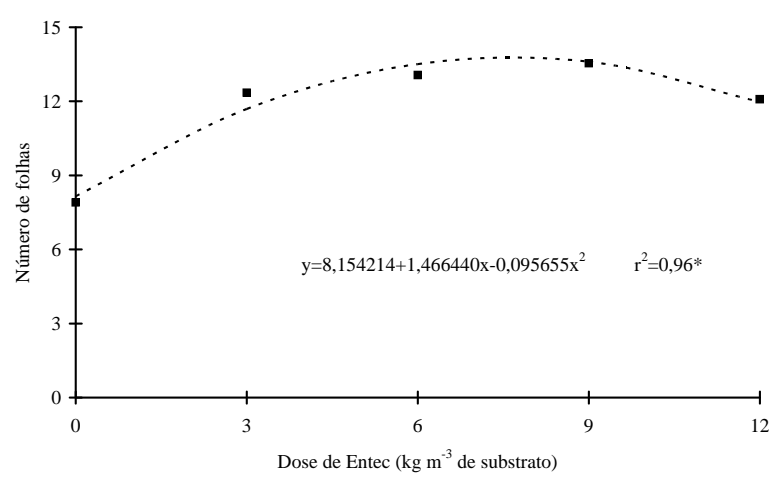

FIGURA 4 - Número de folhas de mudas de maracujazeiro 'Amarelo' em função das doses de Entec ${ }^{\circledR}$. CassilândiaMS, 2005. 
O fertilizante também proporcionou efeitos positivos nas variáveis matéria seca da parte aérea, matéria seca da raiz e matéria seca total. Para a matéria seca da parte aérea, as doses de Entec ${ }^{\circledR}$ tiveram um efeito positivo até a dose máxima de $5,52 \mathrm{~kg} \mathrm{~m}^{-3}$ do fertilizante, em que o valor desta variável foi de $6,70 \mathrm{~g}$. Já para a matéria seca da raiz a resposta das dosagens de fertilizante foi positiva até a dose de 6,33 $\mathrm{kg} \mathrm{m}^{-3}$ do fertilizante, quando foi obtido o maior valor para esta variável que foi de $0,81 \mathrm{~g}$. Para a matéria total (soma da matéria seca da parte aérea e matéria seca da raiz) houve um efeito também quadrático, sendo que a dose máxima de $5,60 \mathrm{~kg} \mathrm{~m}^{-3}$ do fertilizante proporcionou um valor para esta variável de 7,50g (Figura 5).

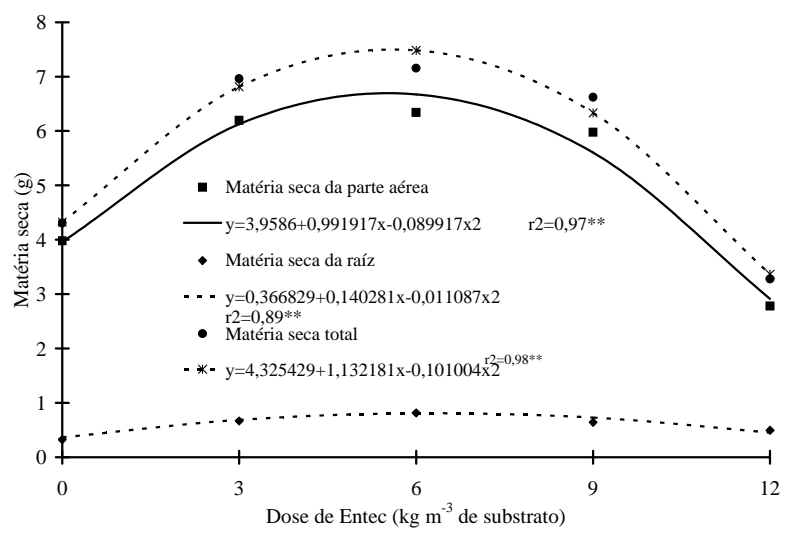

FIGURA 5 - Matéria seca da parte aérea, da raiz e total de mudas de maracujazeiro 'Amarelo' em função das doses de Entec ${ }^{\circledR}$. Cassilândia-MS, 2005.

De maneira geral, a parir da dosagem $6,0 \mathrm{~kg} \mathrm{~m}^{-3}$ do Entec ${ }^{\circledR}$ houve efeito contrário, caracterizado como super dosagem de $\mathrm{N}$, podendo ter ocorrido diminuição do $\mathrm{pH}$ do substrato, ocasionado por uma possível liberação do $\mathrm{H}^{+}$produzidos durante o processo de nitrificação do produto aplicada, conforme é relatado por Decarlos Neto et al. (2002) ou ter ocasionado um desequilíbrio nutricional pelo excesso do $\mathrm{N}$ nas plantas. Resultados semelhantes foram encontrados Teixeira et al. (2004), que verificaram que a utilização de sulfato de amônio em cobertura proporcionou em média, um incremento na altura das mudas de mamoeiro $112,5 \%$ superiores as mudas que não foram adubadas com $\mathrm{N}$ em cobertura independente do substrato utilizado. Já Decarlos Neto et al. (2002) verificaram queda da altura dos porta-enxertos de citros com a utilização de elevadas dosagens de $\mathrm{N}$ (3200 $\mathrm{mg} \mathrm{N} \mathrm{dm}^{-3}$ ), propagados em tubetes.

Utilizando adubação nitrogenada e diferentes substratos no desenvolvimento de mudas de maracujazeiro-amarelo, Mendonça et al. (2004) concluíram que a utilização de adubações nitrogenada em cobertura em dosagem de até $2000 \mathrm{mg} \mathrm{N} \mathrm{dm}^{-3}$ garante melhor qualidade na formação de mudas de maracujazeiro amarelo. E que dosagens elevadas deste nitrogênio promoveram efeitos depressivos nas mudas.

\section{CONCLUSÕES}

Para todas as características avaliadas houve efeito significativo das doses do fertilizante Entec ${ }^{\circledR}$. Sendo dosagens de até $6 \mathrm{~kg} \mathrm{~m}^{-3}$ indicadas para a produção de mudas de maracujazeiro 'Amarelo', visando a obtenção de mudas de boa qualidade e bem nutridas. Dosagens elevadas deste fertilizante promoveram efeitos depressivos nas mudas.

\section{REFERÊNCIAS BIBLIOGRÁFICAS}

DECARLOS NETO, A. Adubação e nutrição nitrogenada de porta-enxertos de citros, semeados em tubetes. 2000. 131 f. Dissertação (Mestrado) - Universidade Federal de Viçosa, Viçosa, 2000.

DECARLOS NETO, A.; SIQUEIRA, D. L. de; PERREIRA, P. R. G.; ALVAREZ, V. H. Crescimento de porta-enxertos de citros em tubetes influenciados por doses de N. Revista Brasileira de Fruticultura, Jaboticabal, v. 24, n. 1, p. 199203, 2002.

GOMES, F. P. Curso de estatística experimental. 14. ed. Piracicaba: USP, 2000. 477 p.

FERREIRA, D. F. Análise estatística por meio do SISVAR (Sistema para Análise de Variância) para Windows versão 4.0. In: REUNIÃO ANUAL DA REGIÃO BRASILEIRA DA SOCIEDADE INTERNACIONAL DE BIOMETRIA, 45., 2000, São Carlos. Anais... São Carlos: UFSCar, 2000. p. 255258.

LOPES, A. S. Nitrogênio. In: Manual de fertilidade do solo. São Paulo: Instituto da Potassa \& Fosfato, 1989. p. 49-62.

MALAVOLTA, E. Elementos de nutrição mineral de plantas. São Paulo: Cores, 1980. 245 p. 
MENDONCA, V.; ARRUDA, N. A. A.; TEIXEIRA, G. A.; SOUZA, H. A.; GURGEL, R. L. S.; FERREIRA, E. A.; RAMOS, J. D. Adubação nitrogenada e diferentes substratos no desenvolvimento de mudas de maracujazeiro-amarelo. In: CONGRESSO DA PÓSGRADUAÇÃO DA UFLA, 13., 2004, Lavras. Anais... Lavras: UFLA, 2004. CD-ROM.

RAIJ, B. van. Avaliação da fertilidade do solo. Piracicaba: Instituto da Potassa \& Fosfato, 1981. 142 p.

RUFTY, T. W.; MACKOWN, C. T.; VOLK, R. J. Alteration in nitrogen assimilation and partitioning in nitrogen stressed plants. Physiologia Plantarum, [S.1.], v. 79, p. 8595, 1990.
SIQUEIRA, D. L. de; ESPOSTI, M. D. D.; NUNES, E. S.; VERGUTZ, L.; BRAZ, V. B.; CAIXETA, S. L. Produção de mudas de maracujazeiro amarelo (Passiflora edulis $\mathrm{f}$. flavicarpa DEG.) em recipientes e adubadas com doses de nitrogênio. In: CONGRESSO BRASILEIRO DE FRUTICULTURA, 17., 2002, Belém. Anais... Belém: SBF, 2002. CD-ROM.

TEIXEIRA, J. D.; PEIXOTO, J. R.; VASCONCELOS, D. R.; PIRES, M. de C.; FLEURY, R. C.; MELO, B. Desenvolvimento de mudas de mamoeiro em diferentes substratos químicos e orgânicos, sob telado. In: CONGRESSO BRASILEIRO DE FRUTICULTURA, 18., 2004, Florianópolis. Anais... Florianópolis: SBF, 2004. CDROM. 